\title{
Efficacy of a reduced pill burden on therapeutic adherence to calcineurin inhibitors in renal transplant recipients: an observational study
}

This article was published in the following Dove Press journal:

Patient Preference and Adherence

9 January 2014

Number of times this article has been viewed

\author{
Massimo Sabbatini' \\ Gianluca Garofalo' \\ Silvio Borrelli² \\ Sossio Vitale' \\ Massimiliano Torino' \\ Domenico Capone ${ }^{3}$ \\ Luigi Russo 3 \\ Antonio Pisani' \\ Rosa Carrano' \\ Riccardo Gallo' \\ Stefano Federico' \\ 'Nephrology, Department of Public \\ Health, University Federico II of \\ Naples, ${ }^{2}$ Department of Nephrology, \\ Second University of Naples, \\ ${ }^{3}$ Department of Neurosciences, Unit \\ of Clinical Pharmacology, University \\ Federico II of Naples, Naples, Italy
}

Correspondence: Massimo Sabbatini Medical Therapy of Renal

Transplantation, Department

of Public Health, University Federico II,

50 Via Alessandro Manzoni, Naples,

Campania 80I23, Italy

Tel/fax +39 08I 7462614

Email sabbatin@unina.it
Purpose: The aim of this study was to determine the prevalence of nonadherence in a cohort of renal transplant recipients (RTRs) and to evaluate prospectively whether more intense clinical surveillance and reduced pill number enhanced adherence.

Patients and methods: The study was carried out in 310 stable RTRs in whom adherence, life satisfaction, and transplant care were evaluated by specific questionnaires (time 0 ). The patients under tacrolimus (TAC; bis in die [BID]) were then shifted to once-daily TAC (D-TAC) to reduce their pill burden (Shift group) and were followed up for 6 months to reevaluate the same parameters. Patients on cyclosporin or still on BID-TAC constituted a time-control group.

Results: The prevalence of nonadherence was $23.5 \%$ and was associated with previous rejection episodes $(P<0.002)$, and was inversely related to Life Satisfaction Index, anxiety, and low glomerular filtration rate (minimum $P<0.03$ ). Nonadherent patients were significantly less satisfied with their medical care and their relationships with the medical staff. A shift from BID-TAC to D-TAC was performed in 121 patients, and the questionnaires were repeated after 3 and 6 months. In the Shift group, a reduction in pill number was observed $(P<0.01)$, associated with improved adherence after 3 and 6 months $(+36 \%, P<0.05$ versus basal), with no change in controls. Decreased TAC trough levels after 3 and 6 months $(-9 \%)$, despite a slight increase in drug dosage $(+6.5 \%)$, were observed in the Shift group, with no clinical side effects.

Conclusion: The reduced pill burden improves patients' compliance to calcineurin-inhibitors, but major efforts in preventing nonadherence are needed.

Keywords: adherence, calcineurin inhibitors, once-daily tacrolimus, renal transplant

\section{Introduction}

Ten years ago, the World Health Organization declared nonadherence to treatment as a major public health problem ${ }^{1}$ that may result in disease progression, increased health care costs, and even premature death in patients with chronic diseases, ${ }^{2}$ including renal transplant recipients (RTRs), especially prone to nonadherence because of the complexity and lifelong character of their immunosuppressive therapeutic regimen. ${ }^{3}$

In clinical controlled trials, nonadherence to treatment ranges between $43 \%$ and $78 \%,{ }^{2}$ and similar results are described with immunosuppressive agents (ISAs) in RTRs $(18 \%-68 \%)$, with such wide ranges reflecting the difficulty of correctly defining and quantifying the phenomenon. ${ }^{4-7}$

A recent consensus conference concluded that nonadherence to ISAs "is more prevalent than previously assumed, is difficult to measure accurately, confers worse outcomes, occurs for a variety of reasons, and is hard to change from a behavioral perspective." ${ }^{\circ}$ Therefore, it is not surprising that nonadherence represents 
the third-leading cause of graft loss after rejections and infections, ${ }^{9}$ is associated with reduced 5 -year graft survival, ${ }^{10}$ has sevenfold-higher odds of graft loss, ${ }^{11}$ and accounts for about half of the graft failures due to rejection. ${ }^{12}$

Nonadherence is a complex and challenging problem, and a better knowledge of its basis and of its appropriate remedies could dramatically improve transplant outcomes, since understanding patient behaviors and their daily problems with grafts could clarify the mechanisms leading to it.

It is well documented that patients' lack of education regarding ISAs and the frequency of drug doses are two important factors leading to nonadherence, ${ }^{7,13}$ as well as that the reduction of pill burden and patient education should be considered as priorities for action to improve therapeutic adherence, these being the easiest to modify. ${ }^{14}$ The recent introduction to the market of a once-daily tacrolimus formulation (D-TAC) offered the opportunity to evaluate whether the shift from a double (bis in die [BID]-TAC) to a single daily administration of the drug may enhance adherence by reducing the number of pills.

A randomized trial by Kuypers et al recently showed that the switch to D-TAC significantly improved implementation by patients of the therapeutic regimen compared to patients continuing BID-TAC during a 6-month follow-up period. ${ }^{15}$ Our first goal was to confirm these data and to offer further information about different factors potentially involved in determining nonadherence.

Therefore, the aims of the present study were 1) to evaluate the prevalence of nonadherence to calcineurin inhibitors (CNIs) in a cohort of stable RTRs through specific questionnaires, and 2) to ascertain whether a reduction in CNI pill numbers and an "educational plan" (written and oral information associated with more intense clinical surveillance) may prospectively influence nonadherence. As a secondary end point, we also examined the pharmacokinetics of D-TAC to verify its efficacy compared to BID-TAC, since data reported in the current literature are not univocal.

\section{Patients and methods}

\section{Study design}

This was an observational, open-labeled, nonrandomized study. Participation in the study was proposed to 347 RTRs regularly visiting our clinic as outpatients, all first transplants from deceased donors. Inclusion criteria were: age $>18$ years, transplant vintage $>1$ year, absence of cognitive impairment, and ability to read and understand the meaning of questionnaires. Three questionnaires were proposed to all the eligible patients visited during an 8-month time frame to evaluate the prevalence of nonadherence (cross-sectional study, Figure 1). Subsequently, all the patients treated with BID-TAC were invited to take D-TAC to reduce the cumulative daily number of pills (Shift group), whereas patients on cyclosporine and those on BID-TAC refusing the shift $(n=39)$ constituted a time-control group; follow-up of these patients lasted 6 months, in which adherence was reevaluated after 3 and 6 months (prospective study, Figure 1). Thirty-seven patients dropped out of the study: 27 patients due to the need to modify their therapies, since as a prerequisite the patients had to maintain the same daily number of pills throughout the follow-up period, and ten subjects returned to BID-TAC for clinical (gastrointestinal upset, tremors) or bureaucratic reasons; therefore, the basal data refer to 310 patients, 160 under BID-TAC and 150 under cyclosporine.

\section{Cross-sectional study (time 0 )}

To analyze the prevalence of nonadherence, three short questionnaires were proposed to the patients during their medical visit (T0). The first two questionnaires were elaborated for the Transplant Learning Center Program, ${ }^{16}$ aimed at improving and preserving graft function through a better knowledge of the factors affecting the life of RTRs. The sum of the singleitem scores, based on a 5-point Likert scale (0-4), leads to the formulation of two indices: 1) the Life Satisfaction Index (LSI), based on eight questions (score 0-32, with higher values denoting better quality of life); and 2) the Transplant Care Index (TCI), based on six questions (score 0-24, with higher values denoting easier care). Both questionnaires were designed to serve as single composite measures to track transplant-specific quality of life and several issues related to caring for the graft (see Supplementary material).

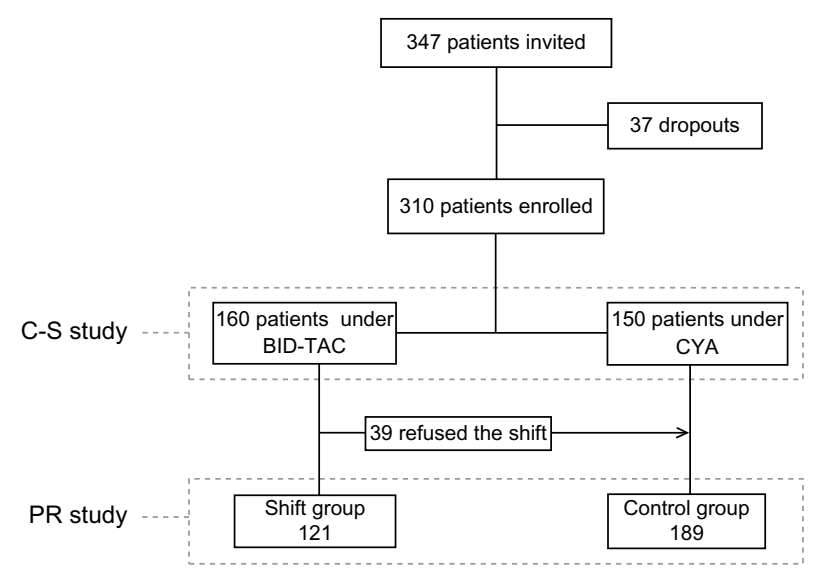

Figure I Flowchart of the study.

Abbreviations: BID-TAC, twice a day; CYA, cyclosporine; C-S, cross-sectional; PR, prospective; Shift, patients shifted from BID-TAC to once-daily TAC; Control, time-control group. 
The third questionnaire was represented by the Immunosuppressant Therapy Adherence Scale (ITAS), based on a four-item scale developed to indicate if transplant recipients were nonadherent to ISAs. ${ }^{17}$ The items of ITAS are designed to explore how often in the last 3 months the patients forgot to take their ISAs, were careless about taking their ISAs, stopped taking their ISAs because they felt worse, missed taking their ISAs for any reason. For each item, the scores were: $3=$ perfect compliance, ie, $0 \%$ nonadherence; $2=1 \%-20 \%$ nonadherence $; 1=21 \%-50 \%$ nonadherence; and $0=$ nonadherence greater than $50 \%$ of the time. Item responses are summed (range $0-12$ ), with the highest score indicating perfect adherence to ISAs. Cukor et al ${ }^{18}$ recently categorized three possibilities based on the level of patients' compliance: perfect adherence (score 12/12), nearly perfect adherence (score 10-11/12), and less than perfect adherence (score $\leq 9 / 12$ ); in our study, only adherence to CNIs was evaluated by ITAS, and all patients with a score $\leq 10$ were considered nonadherent. A specific question was also made to evaluate the presence of anxiety, as previously reported. ${ }^{19}$

\section{Prospective study}

For clinical and ethical reasons, the shift was proposed to all patients previously treated with BID-TAC. After basal evaluation, 121 of 160 patients accepted the conversion to D-TAC (same milligram-for-milligram total daily dose), and constituted the Shift group; patients on cyclosporine and the remaining 39 patients on BID-TAC defined the time-control group ( $\mathrm{n}=189$ ). After the basal questionnaires, the patients of both groups received a printed booklet ("Welcome in the World of Transplantation!," written by MS, NextHealth publishers, Milan, Italy), in which the most common problems of transplant care are easily and extensively reported; the aim and the content of the booklet was explained to the patients, who were strongly encouraged to read it.

Blood samples were withdrawn 7 and 14 days after the beginning of follow-up, to ensure that similar preshift TAC trough levels were reached in the Shift group, modifying the dose of D-TAC when necessary. In control patients, blood was withdrawn to confirm the stability of CNI trough levels. No further modification in D-TAC dose was made in the following months. Three and 6 months after the basal interview (T3 and T6, respectively), the patients were administered the same questionnaires during scheduled visits.

The patients of both groups had the same number of visits and of blood withdrawals throughout the study. The study was performed in accordance with the 1975 Declaration of Helsinki.

\section{D-TAC pharmacokinetics}

In the Shift group, the average value of the last three determinations of BID-TAC trough levels was considered as basal value of the preconversion period. After the shift to D-TAC, blood concentrations of the drug were measured after 7 and 15 days, and then after 3 and 6 months (T3 and T6, respectively).

Blood drug concentrations were measured by the Architect tacrolimus immunoassay (Abbott Laboratories, Abbott Park, IL, USA), with a lower limit of detection of $1.5 \mathrm{ng} / \mathrm{mL}$ and a standard curve range of $0-30 \mathrm{ng} / \mathrm{mL}^{20}$

\section{Statistical analysis}

Data were analyzed using Stata version 12.0 (StataCorp, College Station, TX, USA). Continuous variables are reported as means \pm standard deviation. Comparisons of continuous variables with normal distribution were performed by Student's unpaired $t$-test. For variables with nonnormal distribution, we used unpaired Wilcoxon's nonparametric test. Categorical variables are expressed as percentages and were analyzed by $\chi^{2}$ test.

Multivariable logistic regression analysis was used to identify baseline factors associated with a risk of nonadherence (ITAS <10) at baseline. The model was built by identifying a priori the main potential determinants of nonadherence. The model accounted for demographic (age, sex, job activity, years of school, marital status) and clinical characteristics (diabetes, body mass index, dialysis and transplantation vintage, rejection episodes, anxiety, glomerular filtration rate [GFR]) and questionnaire scores (LSI, TSI).

Doses and trough levels obtained during D-TAC treatment were compared to mean values of BID-TAC treatment by repeated-measures analysis of variance. $P$-values $<0.05$ were considered statistically significant.

\section{Results}

\section{Cross-sectional study}

Table 1 reports demographic and clinical characteristics of the patients under study, and shows well-preserved renal function and satisfactory laboratory data, despite quite a long transplant vintage.

According to our classification, 73 patients were nonadherent (23.5\%): 54 of them (71\%) had an ITAS score of 10 , and the remaining 19 had a score $\leq 9$. All these patients acknowledged forgetfulness as the primary reason for their lower compliance, with some of them feeling worse after CNI administration (3.5\%) or careless about taking their medications $(2.9 \%)$. 
Table I Main data of the whole cohort of patients, and of adherent and nonadherent patients according to the ITAS score ( $\leq$ I0) at baseline

\begin{tabular}{|c|c|c|c|c|}
\hline & All $(n=3 \mid 0)$ & Adherent $(n=234)$ & Nonadherent $(n=76)$ & $P$-value \\
\hline \multicolumn{5}{|l|}{ Demographics } \\
\hline Age (years) & $49.3 \pm 12.1$ & $49.3 \pm 11.8$ & $49.3 \pm 12.6$ & 0.993 \\
\hline Female sex (\%) & 60.9 & 61.1 & 60.6 & 0.928 \\
\hline Diabetes (\%) & 23.8 & 23.5 & 25.0 & 0.790 \\
\hline CVDs (\%) & 16.1 & 17.5 & 11.8 & 0.242 \\
\hline School years & $9.3 \pm 3.1$ & $9.4 \pm 3.1$ & $9.2 \pm 3.0$ & 0.575 \\
\hline Active workers (\%) & 63.5 & 62.0 & 65.8 & 0.594 \\
\hline Living with a partner (\%) & 77.0 & 80.8 & 65.8 & $<0.007$ \\
\hline \multicolumn{5}{|l|}{ Clinic } \\
\hline Blood pressure $(\mathrm{mmHg})$ & $129 \pm 15 / 80 \pm 8$ & $130 \pm \mid 5 / 80 \pm 7$ & $126 \pm 15 / 80 \pm 9$ & $0.142 / 0.988$ \\
\hline BMI $\left(\mathrm{kg} / \mathrm{m}^{2}\right)$ & $26.8 \pm 4.5$ & $26.7 \pm 4.3$ & $26.8 \pm 4.5$ & 0.846 \\
\hline Time since TX (years) & $7.9 \pm 5.0$ & $8.2 \pm 5.1$ & $7.2 \pm 4.7$ & 0.136 \\
\hline Time on dialysis (months) & $36.9 \pm 24.3$ & $38.2 \pm 25.3$ & $32.9 \pm 25.3$ & 0.104 \\
\hline Rejection episodes (\%) & 11.6 & 8.5 & 21 & $<0.003$ \\
\hline Anxiety (\%) & 43.5 & 48 & 29.8 & 0.007 \\
\hline \multicolumn{5}{|l|}{ Laboratory } \\
\hline GFR $\left(\mathrm{mL} / \mathrm{min} / 1.73 \mathrm{~m}^{2}\right)$ & $61.5 \pm 31.6$ & $61.1 \pm 23.9$ & $62.9 \pm 23.3$ & 0.564 \\
\hline Urea $(\mathrm{mg} / \mathrm{dL})$ & $62.0 \pm 27.3$ & $66.3 \pm 33.8$ & $64.9 \pm 27.9$ & 0.744 \\
\hline Hemoglobin (g/dL) & $12.8 \pm 1.7$ & $12.7 \pm 1.7$ & $12.9 \pm 1.7$ & 0.513 \\
\hline Albumin $(g / d L)$ & $4.5 \pm 0.3$ & $4.5 \pm 0.4$ & $4.5 \pm 0.3$ & 0.903 \\
\hline Proteinuria (g/day) & $0.44 \pm 0.84$ & $0.45 \pm 0.80$ & $0.4 I \pm 0.97$ & 0.737 \\
\hline \multicolumn{5}{|l|}{ Immunosuppression } \\
\hline Tacrolimus (\%) & 57.1 & 57.7 & 55.3 & 0.726 \\
\hline Cyclosporine \pm mTOR-I (\%) & 42.9 & 42.3 & 44.7 & 0.711 \\
\hline Steroids (\%) & 77.7 & 78.2 & 76.3 & 0.731 \\
\hline Mycophenolic acid (\%) & 49.6 & 51.7 & 43.4 & 0.209 \\
\hline \multicolumn{5}{|l|}{ Questionnaire scales } \\
\hline LSI & $26.9 \pm 3.9$ & $27.3 \pm 3.9$ & $25.5 \pm 3.7$ & $<0.0005$ \\
\hline $\mathrm{TCl}$ & $18.6 \pm 2.9$ & $18.9 \pm 2.9$ & $17.7 \pm 2.5$ & $<0.006$ \\
\hline ITAS $\leq 10^{\mathrm{a}}(\%)$ & $23.5(n=73)$ & & & \\
\hline
\end{tabular}

Notes: aPercentage of nonadherent patients. Data are expressed as means \pm standard deviation.

Abbreviations: CVDs, cardiovascular diseases; BMI, body mass index; TX, transplantation; GFR, glomerular filtration rate; mTOR, mammalian target of rapamycin; LSI, Life Satisfaction Index; TCI, Transplant Care Index; ITAS, Immunosuppressant Therapy Adherence Scale.

LSI and TCI scores averaged $84.0 \%$ and $77.5 \%$ of their respective maximal scores, denoting a satisfactory quality of life and only minor "barriers" to adequate graft care. When the patients were divided into adherent and nonadherent groups, some differences were noted in marital status and presence of anxiety, higher in adherent patients, whereas rejection episodes were significantly higher in nonadherent patients.

Compared to compliant patients, nonadherent patients showed a reduction in both LSI $(P<0.0005)$ and TCI $(P<0.006)$, with interesting differences in specific items of both indices that mostly indicated difficult relationships with either their partners or the transplant team, and the presence of specific "barriers" to an adequate transplant care (Table 2).

The logistic regression analysis (Table 3) showed that nonadherence to CNIs was significantly predicted by previous rejection episodes $(P<0.002)$, whereas the presence of high LSI values and anxiety represented "protective factors", favoring patients compliance; interestingly, GFR values below $60 \mathrm{~mL} /$ minute were associated with better adherence, but no relationship was observed with the cumulative number of pills, age, sex, living with a partner, or level of school education.

\section{Prospective study}

In the prospective study, the patients were divided into two groups: the Shift group, which included patients accepting the shift to D-TAC ( $\mathrm{n}=121)$, and the time-control group, which consisted of 150 patients on cyclosporine and 39 on BID-TAC refusing the shift $(\mathrm{n}=189)$ who had similar demographic characteristics. Beyond the differences in CNI use, significant differences in the controls were observed in transplant vintage, rejection episodes, and LSI score. 
Table 2 Main significant differences in average scores of specific items of Life Satisfaction Index and Transplant Care Index between adherent and nonadherent patients

\begin{tabular}{llll}
\hline Item & Adherent & Nonadherent & $\boldsymbol{P}$-value \\
\hline Relationship with medical staff & $3.91 \pm 0.43$ & $3.49 \pm 0.61$ & $<0.0007$ \\
Received health care & $3.84 \pm 0.4 \mathrm{I}$ & $3.72 \pm 0.55$ & $<0.04$ \\
Relationship with partner & $3.07 \pm 1.59$ & $2.29 \pm 1.82$ & $<0.0004$ \\
Life in general & $3.45 \pm 0.77$ & $3.04 \pm 0.60$ & $<0.0002$ \\
Keeping scheduled follow-up & $3.86 \pm 0.39$ & $3.50 \pm 0.85$ & $<0.0006$ \\
visits & & & \\
Following a diet & $2.51 \pm 0.43$ & $2.10 \pm 0.99$ & $<0.002$ \\
Taking medicines as prescribed & $3.65 \pm 0.62$ & $3.10 \pm 0.77$ & $<0.000$ I
\end{tabular}

Note: Scores range between 0 and 4, with higher scores denoting better condition and/or fewer difficulties.

At T0 (Table 4), the prevalence of nonadherent patients and the cumulative daily number of pills were similar in the two groups under study. The conversion to D-TAC in the Shift group resulted in a significant and stable reduction in the daily number of pills (10.7 \pm 4.1 versus (vs) $13.3+4.7$, $P<0.01$ ), which conversely did not vary throughout the study in the control group.

Three months after the shift (T3), adherence in the Shift group significantly improved: seven patients reached an ITAS score $>10(P<0.05$ vs T0 $)$, and a further three subjects became adherent at T6 ( $P<0.05$ vs T0); conversely, no change was observed in the time-control group (Figure 2).

There was a modest though significant reduction in LSI observed at T0 in the control group compared to the Shift group (Table 4), which persisted throughout the study; conversely, TCI score was similar between the two groups at baseline and did not vary thereafter.

No significant modification was observed in estimated GFR or in the main laboratory data in both groups, and

Table 3 Factors predictive of nonadherence at baseline in the whole cohort of patients $(n=3 \mid 0)$

\begin{tabular}{|c|c|c|}
\hline & Odds ratio $(95 \% \mathrm{CI})$ & $P$-value \\
\hline Age & $\mathrm{I} .00(0.97-1.03)$ & 0.993 \\
\hline Female sex & $1.12(0.54-1.84)$ & 0.984 \\
\hline School years & $0.97(0.88-1.07)$ & 0.587 \\
\hline Active worker (yes vs no) & $1.03(0.56-1.91)$ & 0.920 \\
\hline Living with a partner & $0.88(0.38-2.04)$ & 0.770 \\
\hline Time on dialysis & $0.99(0.98-1.00)$ & 0.126 \\
\hline Time since $\mathrm{TX}$ & $0.94(0.89-1.01)$ & 0.070 \\
\hline Rejection episodes & $4.08(1.67-9.98)$ & 0.002 \\
\hline Life Satisfaction Index & $0.29(0.12-0.70)$ & 0.006 \\
\hline Transplant Care Index & $0.67(0.33-1.35)$ & 0.265 \\
\hline Anxiety (\%) & $0.24(0.12-0.47)$ & $<0.0001$ \\
\hline Number of pills & I.0I (0.95-I.07) & 0.816 \\
\hline GFR $<60 \mathrm{~mL} / \mathrm{min} / 1.73 \mathrm{~m}^{2}$ & $0.49(0.26-0.93)$ & 0.028 \\
\hline
\end{tabular}

Abbreviations: $\mathrm{Cl}$, confidence interval; $\mathrm{TX}$, transplantation; GFR, glomerular filtration rate; vs, versus.
Table 4 Basal data (T0) of the patients of the Shift and control groups

\begin{tabular}{|c|c|c|c|}
\hline & $\begin{array}{l}\text { Shift } \\
(n=|2|)\end{array}$ & $\begin{array}{l}\text { Control } \\
(n=189)\end{array}$ & $P$-value \\
\hline \multicolumn{4}{|l|}{ Demographics } \\
\hline Age (years) & $47.9 \pm 12.2$ & $49.7 \pm 12.0$ & 0.209 \\
\hline Female sex (\%) & 61.7 & 53.7 & 0.176 \\
\hline Diabetes (\%) & 21.5 & 27.5 & $0.24 I$ \\
\hline School years & $9.8 \pm 3.4$ & $9.0 \pm 2.8$ & 0.025 \\
\hline Active worker (\%) & 67.0 & 61.1 & 0.307 \\
\hline Living with a partner (\%) & 84.3 & 73.7 & 0.031 \\
\hline \multicolumn{4}{|l|}{ Clinic } \\
\hline BMI $\left(\mathrm{kg} / \mathrm{m}^{2}\right)$ & $26.6 \pm 4.4$ & $27.0 \pm 4.5$ & 0.496 \\
\hline $\begin{array}{l}\text { Time since transplant, } \\
\text { years (range) }\end{array}$ & $6.3(3.6-8.5)$ & $7.5(4.1-11.0)$ & 0.010 \\
\hline $\begin{array}{l}\text { Time on dialysis, } \\
\text { months (range) }\end{array}$ & $33(18-50)$ & $36(18-49)$ & 0.415 \\
\hline Rejection episodes (\%) & 8.0 & 14.8 & 0.028 \\
\hline \multicolumn{4}{|l|}{ Laboratory } \\
\hline GFR $\left(\mathrm{mL} / \mathrm{min} / 1.73 \mathrm{~m}^{2}\right)$ & $65 \pm 23$ & $63 \pm 23$ & 0.355 \\
\hline Urea $(\mathrm{mg} / \mathrm{dL})$ & $60.1 \pm 27.7$ & $63.7 \pm 27.3$ & 0.261 \\
\hline Hemoglobin (g/dL) & $13.0 \pm 1.7$ & $12.7 \pm 1.7$ & 0.119 \\
\hline Albumin $(\mathrm{g} / \mathrm{dL})$ & $4.5 \pm 0.3$ & $4.4 \pm 0.4$ & 0.011 \\
\hline \multicolumn{4}{|l|}{ Immunosuppressive therapy } \\
\hline Tacrolimus (\%) & 100 & 20.6 & \\
\hline Cyclosporine (\%) & 0 & 79.4 & \\
\hline Steroids (\%) & 80.2 & 78.4 & 0.722 \\
\hline Mycophenolic acid derivatives (\%) & 43.8 & 51.5 & 0.197 \\
\hline Daily number of pills (n) & $13.3 \pm 4.5$ & $13.9 \pm 4.7$ & 0.266 \\
\hline \multicolumn{4}{|c|}{ Daily number of pills after shift $(n) \mid 0.7 \pm 4 . I^{a}$} \\
\hline \multicolumn{4}{|l|}{ Questionnaire scales } \\
\hline LSI & $27.8 \pm 3.2$ & $26.4 \pm 4.1$ & 0.002 \\
\hline $\mathrm{TCl}$ & $18.6 \pm 2.6$ & $18.6 \pm 3.1$ & 0.768 \\
\hline ITAS $\leq 10^{\mathrm{b}}(\%)$ & $23.1(n=28)$ & $23.8(n=45)$ & 0.652 \\
\hline
\end{tabular}

Notes: ${ }^{2} P<0.01$ versus daily number of pills of Shift group; bercentage of nonadherent patients. Data are expressed as means \pm standard deviation or medians \pm interquartile range.

Abbreviations: BMI, body mass index; GFR, glomerular filtration rate; LSI, Life Satisfaction Index; TCI, Transplant Care Index; ITAS, Immunosuppressant Therapy Adherence Scale.

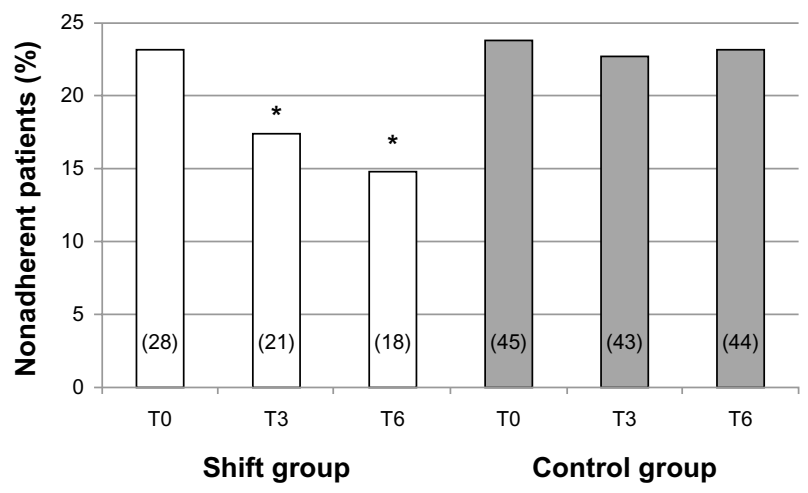

Figure 2 Prevalence of nonadherence in the two groups under study throughout the observation period, expressed as percentage value; the absolute number of patients is reported in columns (T0 $=$ basal; $\mathrm{T} 3$ and $\mathrm{T} 6=$ after 3 and 6 months of follow-up, respectively).

Note: $* P<0.05$ versus T0. 
no rejection episodes or infectious diseases were recorded throughout the follow-up period. Twelve patients complained of minor side effects (pruritus, tremors, gastrointestinal upset) that did not require treatment.

\section{D-TAC pharmacokinetics}

Data of the pharmacokinetic study are represented in Figure 3. After the shift, small adjustments of D-TAC doses were necessary on days 7 and $15(+1.7 \%$ and $+6.5 \%$ vs T0, respectively; $P<0.03$ ), to bring drug concentrations back to basal values; no further change was made thereafter. After 3 and 6 months of D-TAC fixed doses, trough levels progressively declined $(-8.7 \%$ and $-9.2 \%$ vs $\mathrm{T} 0$, respectively, both $P<0.03$ ), but always remained in the recommended therapeutic range.

\section{Discussion}

The results of the present study confirm the high prevalence of nonadherence to CNIs in our RTRs, and demonstrate that the pill burden represents an obstacle to patients' compliance to CNIs. However, despite the significant improvement in patients' adherence after the shift to D-TAC, these data prove that $64 \%$ of nonadherent patients did not change their behavior, even when the number of pills was reduced and greater clinical attention was provided.

Since nonadherence to ISAs is the leading preventable cause of graft loss, to identify noncompliant patients should represent a priority for the transplant team. There are many factors associated with nonadherence: lack of appropriate instructions from health care providers, elevated number of pills, forgetfulness, intentional failure to consume the medication, and drug adverse effects. ${ }^{21}$ It seems clear that a greater effort by medical teams in offering appropriate education and the widest reduction of the "barriers" that may favor nonadherence should be combined to modify patients' wrong habits.

A recent consensus conference ${ }^{14}$ established three priorities of action to reduce the incidence of nonadherence to ISAs - lower pill burden, better patient education, and adequate peer support for patients - as the easiest factors to modify. This justifies our focus on these priorities, evaluated by LSI and TCI, and also psychological or practical barriers that may condition patients' compliance.

The prevalence of nonadherence was substantially high, despite our "strict" definition of nonadherence (ITAS score $\leq 10$ ); some studies, in fact, claim an adherence $<80 \%$ (ITAS $<10$ ) as the minimum threshold ${ }^{22,23}$; our choice takes into account that questionnaires underestimate the prevalence of nonadherence, due to the reluctance of patients to admit their mistakes or to the limits of their memory. ${ }^{24}$ Nonetheless, compared to electronic devices, pharmacy records, or druglevel monitoring, questionnaires represent a reliable source in evaluating nonadherence in large cohorts of patients, despite their inherent limitations. In particular, ITAS has been validated by correlating composite item scores with refill-record adherence rates, serum ISA concentrations, and episodes of graft rejection or increased serum creatinine, ${ }^{17}$ and is practical, feasible, and cost-effective.

In this study, the main predictor of nonadherence was the previous presence of rejection episodes, an obvious

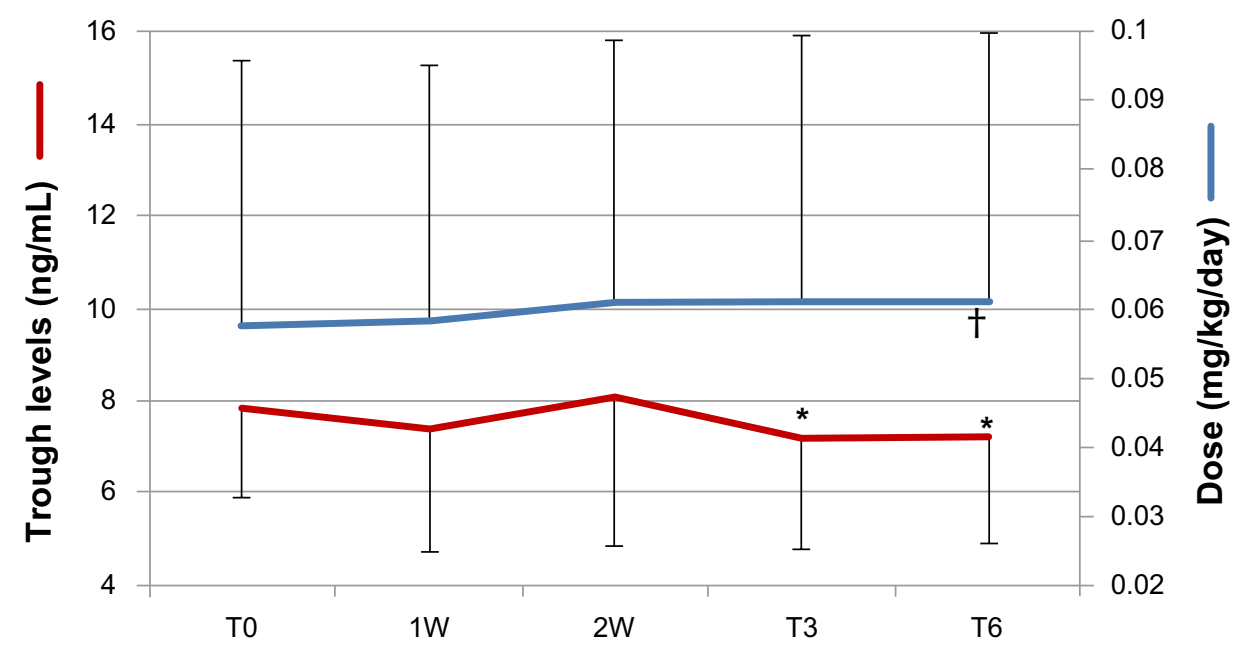

Figure 3 Doses (blue line) and trough levels (red line) of once-daily tacrolimus (D-TAC) throughout the observation period in patients of the Shift group. T0 represents the mean value of the last three bis in die TAC trough levels and doses before the shift; IW and $2 \mathrm{~W}$ represent the determinations of trough levels I week and I5 days after the shift and the consequent changes in D-TAC doses; T3 and T6 represent the modifications in D-TAC trough levels after 3 and 6 months of follow-up, when the doses of D-TAC were fixed.

Notes: $* P<0.003, \mathrm{~T} 3$ and T6 versus T0, $\dagger P<0.003$ versus T0. 
consequence of low compliance to immunosuppressors. Positive factors in preventing it were a better quality of life, which certainly predisposes to better care of the graft, and the presence of anxiety or lower levels of GFR, probably a consequence of the greater attention to medical prescriptions by patients who fear to lose their graft. Contrary to previous studies, no relationship was observed with sex, marital status, or level of education, which was quite low in our patients. ${ }^{9,11,25}$

An interesting finding of the cross-sectional study was the difference in specific items of both LSI and TCI between adherent and nonadherent patients, which showed how these latter patients had difficult relationships with the transplant team, lower satisfaction with the health care they receive, or difficulties in attending the scheduled visits. These patients clearly need greater attention from medical personnel, stressing our crucial role in enhancing therapeutic compliance.

Beyond the beneficial effects of the reduced pill burden on adherence, reported in different solid-organ grafts, ${ }^{15,26,27}$ our prospective study offers additional information about the education of patients and closer clinical surveillance.

The absolute lack of changes in patients' adherence in our time-control group, despite considerably greater clinical attention, clearly suggests that any educational plan should start immediately after the transplant, and should be intensively maintained thereafter by dedicated personnel, ${ }^{28}$ due to the refractoriness of these patients to modify consolidated habits in the long term.

Our data suggest that D-TAC may represent an option to increase patients' compliance, despite its higher cost $(+5.4 \%)$, since its pharmacokinetic profile is comparable to BID-TAC, with only minor dose adjustments and fluctuations of its plasma levels that did not expose the patients to rejection episodes or undesirable side effects. Indeed, reductions in blood TAC concentrations averaged $9.2 \%$ after 6 months of follow-up, a value quite different from the one reported in a recent retrospective study, in which the shift to D-TAC determined a $21.7 \%$ decrease in trough levels despite the concomitant rise in its doses (17.2\%), during a 6-month follow-up..$^{29}$ Differences in patients' demographics, in their therapeutic compliance, or in pharmacogenomics may account for this discrepancy. Our data, however, are in line with those by Guirado et al, ${ }^{30}$ who found a similar decrease in TAC trough levels after the shift $(-9.2 \%)$, with a small increase in dose $(+1.24 \%)$.

The main limit of the study derives from its observational nature and the unavoidable selection bias of patients of the prospective study. As a consequence, differences existed at baseline between the groups in transplant time, rejection episodes, and LSI score that make any comparison difficult. It must be stressed, however, that the control group was just a time-control group, in which the pill burden did not vary, useful in understanding, although indirectly, the effects of our "educational plan". According to this point of view, differences in transplant vintage or in rejection rate should not influence the interpretation of data, considering also that the prevalence of nonadherence was comparable between the groups at baseline.

Instead, a strength of the paper resides in the effort of maintaining the same pill burden and in providing identical clinical surveillance to all patients throughout the follow-up period. It is well known, in fact, that the frequency of visits and blood withdrawals may positively affect patients' compliance..$^{30}$

In conclusion, this study confirms that therapeutic adherence is a multidimensional phenomenon determined by the interaction of different "dimensions", of which patient-related factors represent just one variable. Our study demonstrates that pill burden helps to reduce nonadherence, but the common belief that patients are solely responsible for taking their treatment is misleading and does not consider how other factors, also related to health care providers, may affect the patients' capability to comply with our prescriptions.

Therefore, if it is strongly advisable to consider the total number of pills when providing optimal therapy to any patient, we should not forget difficult relationships with the medical team of nonadherent patients, which represent an important factor leading to wrong behaviors.

Greater effort should be made to assure patients' compliance to treatment, keeping in mind that adherence requires a lifelong commitment from both patients and clinicians and that we tend to overestimate patients' understanding and consciousness. This, associated with the reduced pill burden, a careful and early "educational plan", and an increased number of visits when nonadherence is even suspected, might lead to improved compliance and a better outcome of the graft.

\section{Disclosure}

The authors report no conflicts of interest in this work.

\section{References}

1. World Health Organization. Adherence to Long-Term Therapies: Evidence for Action. Geneva: WHO; 2003. Available from: http:// www.who.int/chp/knowledge/publications/adherence_full_report.pdf. Accessed September 12, 2012.

2. Prendergast MB, Gaston RS. Optimizing medication adherence: an ongoing opportunity to improve outcomes after kidney transplantation. Clin J Am Soc Nephrol. 2010;5:1305-1311. 
3. Dew MA, DiMartini AF, De Vito Dabbs A, et al. Rates and risk factors for nonadherence to the medical regimen after adult solid organ transplantation. Transplantation. 2007;83:858-873.

4. Siegal BR, Greenstein SM. Postrenal transplant compliance from the perspective of African-Americans, Hispanic-Americans, and AngloAmericans. Adv Ren Replace Ther. 1997;4:46-54.

5. Greenstein S, Siegal B. Compliance and noncompliance in patients with a functional renal transplant: a multicenter study. Transplantation. 1998;66:1718-1726.

6. Raiz LR, Kilty K, Henry ML, Ferguson RM. Medication compliance following renal transplantation. Transplantation. 1999;68:51-55.

7. Vasquez EM, Tanzi M, Benedetti E, Pollak R. Medication noncompliance after kidney transplantation. Am J Health Syst Pharm. 2003;60:666-669.

8. Fine RN, Becker Y, De Geest S, Eisen H, Ettenger R. Nonadherence consensus conference summary report. Am J Transplant. 2009;9: 35-41.

9. Didlake RH, Dreyfus K, Kerman RH, van Buren CT, Kahan BD. Patient noncompliance: a major cause of late graft failure in cyclosporinetreated renal transplants. Transplant Proc. 1988;20 Suppl 3:63-69.

10. de Geest S, Borgermans L, Gemoets H, et al. Incidence, determinants, and consequences of subclinical noncompliance with immunosuppressive therapy in renal transplant recipients. Transplantation. 1995;59: 340-347.

11. Butler JA, Roderick P, Mullee M, Mason JC, Peveler RC. Frequency and impact of nonadherence to immunosuppressants after renal transplantation: a systematic review. Transplantation. 2004;77:769-776.

12. Sellares J, de Freitas DG, Mengel M, et al. Understanding the causes of kidney transplant failure: the dominant role of antibody-mediated rejection and nonadherence. Am J Transplant. 2012;12:388-399.

13. Weng FL, Israni AK, Joffe MM, Hoy T, Gaughan CA. Race and electronically measured adherence to immunosuppressive medications after deceased donor renal transplantation. JAm Soc Nephrol. 2005; 16: 1839-1848.

14. O’Grady JG, Asderakis A, Bradley R, et al. Multidisciplinary insights into optimizing adherence after solid organ transplantation. Transplantation. 2010;89:627-632.

15. Kuypers DR, Peeters PC, Sennesael JJ, et al. Improved adherence to tacrolimus once-daily formulation in renal recipients: a randomized controlled trial using electronic monitoring. Transplantation. 2013;95: 333-339.

16. Matas AJ, Halbert RJ, Barr ML, et al. Life satisfaction and adverse effects in renal transplant recipients: a longitudinal analysis. Clin Transplant. 2002;16:113-121.
17. Chisholm MA, Lance CE, Williamson GM, Mulloy LL. Development and validation of the immunosuppressant therapy adherence instrument (ITAS). Patient Educ Couns. 2005;59:13-20.

18. Cukor D, Rosenthal DS, Jindal RM, Brown CD, Kimmel PL. Depression is an important contributor to low medication adherence in hemodialyzed patients and transplant recipients. Kidney Int. 2009;75:1223-1229.

19. Sabbatini M, Crispo A, Pisani A, et al. Sleep quality in renal transplant patients: a never investigated problem. Nephrol Dial Transplant. 2005;20:194-198.

20. Wallemacq P, Goffinet JS, O'Morchoe S, et al. Multi-site analytical evaluation of the Abbott ARCHITECT tacrolimus assay. Ther Drug Monit. 2009;31:198-204.

21. Chisholm MA, Mulloy LL, DiPiro JT. Comparing renal transplant patients' adherence to free cyclosporine and free tacrolimus immunosuppressant therapy. Clin Transplant. 2005;19:77-83.

22. Chisholm MA, Vollenweider LJ, Mulloy LL, et al. Renal transplant patient compliance with free immunosuppressive medications. Transplantation. 2000;70:1240-1244

23. Hilbrands LB, Hoitsma AJ, Koene RA. Medication compliance after renal transplantation. Transplantation. 1995;60:914-920.

24. Schäfer-Keller P, Steiger J, Bock A, Denhaerynck K, De Geest S. Diagnostic accuracy of measurement methods to assess non-adherence to immunosuppressive drugs in kidney transplant recipients. $\mathrm{Am} \mathrm{J}$ Transplant. 2008;8:616-626.

25. Kiley DJ, Lam CS, Pollak R. A study of treatment compliance following kidney transplantation. Transplantation. 1993;55:51-56.

26. Beckebaum S, Iacob S, Sweid D, et al. Efficacy, safety, and immunosuppressant adherence in stable liver transplant patients converted from a twice-daily tacrolimus-based regimen to once-daily tacrolimus extended-release formulation. Transpl Int. 2011;24:666-675.

27. Doesch AO, Mueller S, Konstandin M, et al. Increased adherence after switch from twice daily calcineurin inhibitor based treatment to once daily modified released tacrolimus in heart transplantation: a preexperimental study. Transplant Proc. 2010;42:4238-4242.

28. Urstad KH, Øyen O, Andersen MH, Moum T, Wahl AK. The effect of an educational intervention for renal recipients: a randomized controlled trial. Clin Transplant. 2012;26:E246-E253.

29. Hougardy JM, Broeders N, Kianda M, et al. Conversion from Prograf to Advagraf among kidney transplant recipients results in sustained decrease in tacrolimus exposure. Transplantation. 2011;91:566-569.

30. Guirado L, Cantarell C, Franco A, et al. Efficacy and safety of conversion from twice-daily to once-daily tacrolimus in a large cohort of stable kidney transplant recipients. Am J Transplant. 2011;11: 1965-1971. 


\section{Supplementary material}

The transplant learning center indices

Life satisfaction index

Please rate your satisfaction with each of the following in your life within the last month:

1. Your overall health

2. Your relationship with the people who provide your medical care

3. The health care you have received

4. Your relationship with your spouse/partner

5. Your ability to do things for yourself

6. Your appearance

7. The amount of control you have over your life

8. Your life in general.

Five-item scale (0-4, very dissatisfied-very satisfied); maximum score 32, with higher scores denoting a better quality of life.

\section{Transplant care index}

Please rate the level of difficulty you have with the following:

1. Keeping your scheduled follow-up visits

2. Following a regular exercise program

3. Following a healthy and balanced diet

4. Having your tests done as scheduled

5. Taking all of your medicines as prescribed

6. Dealing with the side effects of your medicines.

Five-item scale ( $0-4$, very difficult-very easy); maximum score 24 , with higher scores denoting easier transplant care.

\section{Publish your work in this journal}

Patient Preference and Adherence is an international, peer-reviewed, open access journal focusing on the growing importance of patient preference and adherence throughout the therapeutic continuum. Patient satisfaction, acceptability, quality of life, compliance, persistence and their role in developing new therapeutic modalities and compounds to optimize clinical outcomes for existing disease states are major areas of interest. This journal has been accepted for indexing on PubMed Central. The manuscript management system is completely online and includes a very quick and fair peer-review system. Visit http://www.dovepress.com/ testimonials.php to read real quotes from published authors. 